not determined, but there was no haematological evidence of folic-acid deficiency. Kershaw and Girdwood (1964) found two out of six patients with disseminated carcinoma to have low serum folic-acid levels and increased Figlu excretions, and Girdwood (1953b) has reported evidence of folic-acid deficiency in this condition. The most likely explanation for such cases is that there is an increased demand for folic acid due to the proliferation of malignant cells. Dymock (1964a) has estimated the urinary excretion of urocanic acid and Figlu in 28 patients with malignant disease, and in 24 the outputs were abnormal. He did not measure the serum folic-acid levels, and in 10 cases there was some evidence of liver dysfunction (Dymock, 1964b). It is possible, therefore, that in some cases of disseminated malignancy the abnormal Figlu excretion results from an impairment of hepatic Figlu transferase activity.

A rapid turnover of folic acid may have contributed to the folic-acid deficiency observed in the three patients with lymphosarcoma and the patient with chronic lymphocytic leukaemia. Abnormal Figlu excretions occur frequently in both acute and chronic leukaemias and reticuloses, and in such cases the serum folic-acid levels are often low (Rose, 1964).

\section{Summary}

The excretion of Figlu in the urine has been estimated in 35 patients with a variety of diseases accompanied by intestinal malabsorption. It is concluded that although the Figlu excretion test is of limited value for screening patients with suspected idiopathic steatorrhoea, such a diagnosis is unlikely if the Figlu excretion is normal.

It is suggested that the urinary Figlu excretion and the urinary xylose-excretion test used in combination provide a simple means of assessing jejunal function in patients with small-bowel disease.

I am grateful to Dr. Arthur Jordan for much help and advice during the course of the work and in the preparation of the paper. I wish to thank Dr. E. K. Blackburn, Department of Haematology, United Sheffield Hospitals, for the haematological data, and Dr. S. Varadi, Department of Haematology, City General Hospital, Sheffield, for the serum folic-acid and vitamin- $\mathrm{B}_{12}$ results.

\section{REFERENCES}

Chanarin, I., Anderson, B. B., and Mollin, D. L. (1958). Brit. f. Haemat., 4, 156.

C Bennett, M. C., and Berry, V. (1962). f. clin. Path., 15, 269.

Christiansen, P. A., Kirsner, J. B., and Ablaza, J. (1959). Amer. F. Med., $27,443$.

Deller, D. J., and Witts, L. J. (1962). Quart. F. Med., 31, 71.

Dymock, I. W. (1964a). Lancet, 2, 114.

(1964b). Ibid., 2, 475.

Fourman, L. P. R. (1948). Clin. Sci., 6, 289.

Fowler, D., and Cooke, W. T. (1960). Gut, 1, 67

Frazer, A. C. (1956). Broadsheet 9 (new series) of the Association of Clinical Pathologists.

Gardiner, F. H., and Perez Santiago, E. (1956). Arch. intern. Med., 98, 467.

Girdwood, R. H. (1953a). Lancet, 2, 53.

(1953b). Brit. med. f., 2, 741 .

Herbert, V., and Zalusky, R. (1962). F. clin. Invest., 41, 1263.

Joske, R. A., and Blackwell, J. B. (1959). Lancet, 2, 379.

Kershaw, P. W., and Girdwood, R. H. (1964). Scot. med. F., 9, 201.

Knowles, J. P. (1962). Gut, 3, 42.

and Prankerd, T. A. J. (1962). Clin. Sci., 22, 233.

Kohn, J., Mollin, D. L., and Rosenbach, L. M. (1961). f. clin. Path., 14, 345 .

Merritt, A. D., Rucknagel, D. L., Silverman, M., and Gardiner, R. C. (1962). F. clin. Invest., 41, 1472.

Paulley, J. W., Fairweather, F. A., and Leeming, A. (1957). Lancet, 1, 406.

Rose, D. P. (1964). Ibid., 2, 311.

Shiner, M., Vakil, B. J., and Wilcox, P. B. (1962). Gut, 3, 240.

Tabor, H., and Wyngarden, L. (1958). F. clin. Invest., 37, 824

Wormsley, K. G. (1963). Gut, 4, 261.

Zalusky, R., and Herbert, V. (1961). f. clin. Invest., 40, 1091.

\title{
Myopathy in Metabolic Bone Disease
}

\author{
J. W. PRINEAS, ${ }^{*}$ M.B., M.R.C.P., M.R.C.P.ED. ; A. STUART MASON, $†$ M.D., M.R.C.P. ; \\ R. A. HENSON, $\ddagger$ M.D., F.R.C.P.
}

Brit. med. 9., 1965, 1, 1034-1036

Muscular weakness is often found in patients with metabolic bone disease (Albright and Reifenstein, 1948), but the symptom has attracted little attention in the literature. Indeed, weakness may be the outstanding symptom in primary hyperparathyroidism and osteomalacia, and the clinical picture then simulates progressive primary disease of muscle (Vicale, 1949 ; Dent, 1956 ; Murphy, ReMine, and Burbank, 1960 ; Shy, 1960). Diagnoses of myositis and Guillain-Barré syndrome were made initially in Vicale's two patients with primary hyperparathyroidism. Both showed symmetrical weakness and wasting of the proximal muscles of the limbs, a waddling gait, discomfort on movement, hypotonia, and brisk tendon reflexes, with resolution following parathyroidectomy. $\mathrm{He}$ also described an identical myopathic syndrome in a patient with osteomalacia.

It has been assumed that a disturbance of ionized calcium is directly responsible for the myopathy in both conditions (Murphy et al., 1960 ; Shy, 1960 ; Adams, Denny-Brown, and Pearson, 1962). However, marked weakness has been recorded in osteomalacia in the presence of normal serum calcium (Albright and Reifenstein, 1948 ; Dent, 1963).

In the following report we describe two patients with longstanding proximal muscular weakness, associated in one case with a parathyroid adenoma and osteomalacia, and in the other with osteomalacia and idiopathic steatorrhoea. Possible causes of the muscular disorder are discussed.

\section{Case 1}

A housewife aged 37 was admitted to Maida Vale Hospital in March 1962 complaining of increasing weakness of the arms and legs for eight months. Walking had been affected first, with particular difficulty in mounting stairs. Within two months she was confined to her home on account of the weakness; she could not lift her 3-year-old son from the floor, and required assistance to dress. She subsequently experienced discomfort and occasionally pain in the thighs on movement. She had lost $7 \mathrm{lb}$. $(3,175 \mathrm{~g}$.) in weight since the onset of weakness. For several years she had risen once nightly to micturate, but there had been no excessive thirst or polyuria. She had five normal children.

Examination showed her to be small and thin, but she looked well. Her gait was waddling, and she climbed up herself in rising from the floor. The muscles of the thighs and buttocks were wasted. There was generalized hypotonia. Hip flexion and extension, abduction of the shoulders, and extension of the elbows were markedly

* Senior Registrar, the London Hospital.

t Consultant Endocrinologist, the London Hospital.

$\ddagger$ Consultant Neurologist, the London Hospital ; Physician, the National Hospitals for Nervous Diseases (Maida Vale), London. 
weak. All other movements at the hips and shoulders, elbow flexion, and movements of the knees were moderately weak. There was slight weakness of dorsiflexion of the wrists, but otherwise power was normal distally. The tendon reflexes were brisk and equal, and the plantar responses were flexor. Sensation was normal. No other abnormality was found. The blood-pressure was 120/80.

Investigations.-The urine contained no protein or reducing substances; the deposit was normal and culture sterile. Other findings were: haemoglobin $13 \mathrm{~g} . / 100 \mathrm{ml}$; white blood cells 7,200/c.mm. ; E.S.R. repeatedly less than $14 \mathrm{~mm} . / \mathrm{hr}$. (Westergren); blood W.R. negative; serum proteins 6.5 g. $/ 100 \mathrm{ml}$., with a normal electrophoretic pattern ; L.E. cells absent on two examinations ; Mantoux test positive (O.T. $1: 1,000$ ) ; blood urea $34 \mathrm{mg} . / 100 \mathrm{ml}$.; serum sodium 137, potassium 5, chloride $113 \mathrm{mEq} / 1$. ; chest radiograph normal ; serum creatine-kinase and aldolase within normal limits; Tensilon test negative. Electromyography, with sampling of both biceps and anterior tibial muscles, showed short-duration polyphasic potentials, a full interference pattern, and no evidence of denervation. Muscle biopsy, taken from the quadriceps, revealed scattered atrophic fibres with crowding of sarcolemmal nuclei. The serum calcium was not determined at this stage.

A diagnosis of myopathy of undetermined cause was made, and empirical treatment with prednisone, $10 \mathrm{mg}$. thrice daily, was started; after two weeks the dose was reduced to $10 \mathrm{mg}$. twice daily. Within six weeks discomfort on movement had disappeared and substantial improvement in power was evident. She was able to resume full domestic responsibilities without assistance. However, moderate disability persisted, and in November 1962 she sufferef a spontaneous rib-fracture. Radiographs showed the changes of hyperparathyroidism, with cysts in the femora, tibiae, and metacarpals, subperiosteal erosions in the phalanges, and coarse trabeculation of the pelvic bones. There was loss of bone density in the centre of the vertebral bodies and sclerosis adjacent to the disks. The base and vault of the skull were sclerosed, with occasional small cysts. The teeth were absent. Fine speckled calcification of the kidneys was present. However, the patient was satisfied with her progress and declined further investigation for five months, when she was readmitted to hospital.

At this time she still had difficulty in climbing stairs, could not lift heavy objects, and was unable to rise easily from a chair. Examination showed moderate weakness of hip flexors and quadriceps, almost normal power in the arms, and a slightly waddling gait. Her span exceeded height by $1 \frac{1}{2}$ in. $(38 \mathrm{~mm}$.). The tibiae were tender, although there had been no discomfort in the legs for twelve months. Intravenous pyelography showed no abnormality. Biochemical investigation was carried out at the London Hospital. Serial fasting serum-calcium estimation ranged from 9.2 to 10.7 mg./100 ml. ; serum albumin 4 g./100 ml., serum globulin 2.5 g./ $100 \mathrm{ml}$; ; plasma ionized calcium $6.9 \mathrm{mg} . / 100 \mathrm{ml}$. (Dr. Lyal Watson, University College Hospital); serum inorganic phosphorus 1.7 to $2.7 \mathrm{mg} . / 100 \mathrm{ml}$; alkaline phosphatase 20 to 29 K.A. units. An iliac-crest biopsy showed characteristic changes of osteomalacia but no evidence of osteitis fibrosa. The serum sodium was 140 , potassium 4 , and bicarbonate $21 \mathrm{mEq} / \mathrm{l}$. Renal-function tests were abnormal in that there was an inability to excrete a normal acid load (Wrong and Davies, 1959). The blood urea was $31 \mathrm{mg} . / 100 \mathrm{ml}$. The phosphate excretion index (Nordin and Fraser, 1960) was $+0.186 ; 24$-hour urinary calcium 56-164 mg., 24-hour urinary citrate 119-184 mg., and plasma citrate $2.9 \mathrm{mg}$./ $100 \mathrm{ml}$. A provisional diagnosis of renal tubular acidosis with hyperparathyroidism and osteomalacia was made and the patient was discharged on calciferol, 18,000 i.u. daily, and alkalis.

The serum calcium was followed carefully. Readings remained below $10.6 \mathrm{mg} . / 100 \mathrm{ml}$. for a month, when a rise to $13.2 \mathrm{mg}$./ $100 \mathrm{ml}$. was observed, without any increase in muscular weakness. Treatment with calciferol was stopped, but alkalis were continued, and the serum calcium remained elevated. A 10-day prednisone suppression test (30 mg./day) did not affect the high serum-calcium level, but shortly after stopping prednisone the reading fell to normal levels and remained there. However, the indications for exploring the neck were now definite, and in September $1963 \mathrm{Mr}$. J. E. Richardson removed a parathyroid adenoma weighing $3.9 \mathrm{~g}$. The other parathyroid glands were not seen. Histological examination showed a solid trabecular arrangement of chief cells with very few water-clear cells. After the operation muscular power steadily improved, returning to normal in two months. Alkalis have been continued in treatment of the renal tubular acidosis. There has been no appreciable change in her capacity to excrete an acid load. Muscle power remains normal.

Comment.-Renal tubular acidosis is a well-recognized complication of primary hyperparathyroidism (Cohen, Fitzgerald, Fourman, Griffiths, and de Wardener, 1957 ; Wrong and Davies, 1959), and may persist after parathyroidectomy (Fourman, McConkey, and Smith, 1960). Osteomalacia has been described in primary hyperparathyroidism by Ball (1963), and its presence in our casè indicates a disturbance of vitamin-D metabolism. Davies, Dent, and Willcox (1956) and Beveridge, Vaughan, and Walters (1959) have reported osteosclerosis in primary hyperparathyroidism. No adequate explanation can be offered for the improvement in muscular power which followed treatment with prednisone.

\section{Case 2}

A woman aged 45 was admitted to University College Hospital in January 1964 with a year's history of difficulty in walking. She stated that she could not lift her legs properly when walking in the street, and " had to concentrate to put one leg in front of the other." She found stairs difficult to mount. Her arms " felt tired"; ironing and window-cleaning had become difficult. For six years she had had low back pain, and for three years sudden movement had provoked pains in the knees and thighs. Her stools were pale and tended to float. Occasional episodes of diarrhoea had occurred for many years. Although her appetite was good she had lost $14 \mathrm{lb}$. (6.35 kg.) in weight in the past year. Pernicious anaemia had been diagnosed at the age of 35 , and since then she had received $1,000 \mu \mathrm{g}$. of parenteral vitamin $B_{12}$ weekly.

She was of small build and looked well. The pubis-heel height exceeded pubis-crown height by $2 \frac{1}{4}$ in. $(57 \mathrm{~mm}$.). Her gait was grossly waddling; she climbed up herself on rising from a chair Abduction of the shoulders, extension of the elbows, and trunk flexion were moderately weak. Abduction of the hips was markedly weak ; other hip movements were weak, but accurate assessment was not possible because of guarding. The affected muscles were wasted but not tender. Power was normal distally. There was generalized slight hypotonia, and the tendon reflexes were brisk and symmetrical. The remainder of the neurological examination was negative. The tibiae and lower ribs were tender to pressure.

Investigations. $-X$-ray films revealed a Looser zone in one radius, subperiosteal erosion in the phalanges, pathological fractures of several ribs, and some loss of bone density and an alteration of texture in the spine, skull, and pelvis. No cysts were present, and there was no deformity of the long bones or spine. The serum calcium ranged from 9.6 to $10.4 \mathrm{mg} . / 100 \mathrm{ml}$. (serum S.G. 1026), phosphorus 1.4 to $1.8 \mathrm{mg} . / 100 \mathrm{ml}$., alkaline phosphatase 36 to 48 K.A. units, and 24-hour urinary calcium 200 to $300 \mathrm{mg}$. An iliaccrest biopsy confirmed the presence of osteomalacia with additional features of osteitis fibrosa. Renal-function tests, including acid-load excretion, were normal (Wrong and Davies, 1959). The blood urea was $28 \mathrm{mg} . / 100 \mathrm{ml}$. and the serum sodium 138 , potassium 4.2, chloride 106, and standard bicarbonate $24.5 \mathrm{mEq} / 1$. Six-day stool collections showed an excretion of 13 and $27 \mathrm{~g}$. of fat per day ; marked clumping was seen on micropaque studies of the small bowel ; jejunal biopsy revealed subtotal villous atrophy, establishing the diagnosis of idiopathic steatorrhoea. Electromyography (Dr. E. D. R. Campbell, Royal Free Hospital): Right vastus medialis normal. Exploration of the left vastus medialis and right deltoid showed evidence of a myopathy, with scattered patches of shortduration polyphasic potentials on volition. No muscle biopsy was done.

Seven weeks after starting treatment with a gluten-free diet and dihydrotachysterol, $2 \mathrm{mg}$. daily, pain disappeared completely, and there was a marked improvement in walking. Examination three months later showed slight but definite weakness of the biceps, triceps, deltoids, and all hip movements. A minimal waddling gait persisted.

Comment.-Secondary hyperparathyroidism is a recognized feature of osteomalacia, but in view of the persistently normal total-serum-calcium readings-an unusual finding in osteomalacia due to steatorrhoea-the patient may be developing a parathyroid adenoma. 


\section{Discussion}

The main clinical features in both our patients were proximal muscular weakness and wasting, discomfort on movement, hypotonia, and brisk reflexes. Both showed evidence of osteomalacia and hyperparathyroidism. The same symptoms and signs have been described in previously reported cases of osteomalacia and primary hyperparathyro:dism presenting with proximal myopathy (Vicale, 1949; Murphy et al., 1960). If bone tenderness is also present the syndrome is sufficiently characteristic to be distinguishable from other causes of proximal muscular weakness, even in the absence of other evidence of metabolic bone disease. The muscular disorder most likely to be confused with the myopathy of metabolic bone disease is polymyositis, especially if the widely inclusive criteria of Walton and Adams (1958) are applied. The combination of brisk reflexes and muscular weakness has been wrongly interpreted as evidence of motor-neurone disease (Vicale, 1949), or of an upper-motor-neurone lesion (Payne, 1959). From our experience we conclude that estimation of the serum alkaline phosphatase should be a routine investigation in all cases of proximal myopathy of undetermined cause. The diagnosis of hyperparathyroidism or osteomalacia can usually be established without difficulty, provided the possibility is kept in mind.

The electromyogram in both our patients showed abnormalities of myopathic type without evidence of denervation. This electromyographic pattern was taken to indicate a random loss of muscle fibres within a motor unit or a disturbance at the neuromuscular junction. The scattered atrophic fibres found at muscle biopsy in Case 1 represent a nonspecific abnormality, which may occur in a variety of systemic diseases (Pearson, 1959), and also in a number of muscular disorders, including thyrotoxic myopathy (Adams et al., 1962) and the carcinomatous neuromyopathies (Henson, Russell, and Wilkinson, 1954). Shy (1960) found no abnormality in the muscle biopsy from a patient with weakness ascribed to hyperparathyroidism. However, he noted central nuclei and groups of small fibres, suggesting neurogenic atrophy, in a patient with Milkman's syndrome and weakness not due to hypokalaemia.

Muscular weakness has been mentioned in accounts of patients with osteomalacia due to causes other than idiopathic steatorrhoea (Dent, 1956 ; Shy, 1960 ; Gough, Lloyd, and Wills, 1964). Muscular weakness, responding to treatment with vitamin $\mathrm{D}$, has been reported in association with renal osteodystrophy (Stanbury, 1963). The waddling gait, lordosis, and delay in walking encountered in classical vitamin-D-deficiency rickets, with minimal long-bone and pelvic deformities, have been ascribed to "hypotonia." We suspect these symptoms may prove to be due to metabolic myopathy.

The muscular weakness associated with metabolic bone disease has been attributed to the effects of alterations in the level of ionized calcium on excitability and transmission at the neuromuscular junction (Payne, 1959; Murphy et al., 1960 ; Shy, 1960). The findings in our patients do not support this view. In Case 1 weakness was pronounced over a period of several weeks' close observation, during which time the serum calcium was either normal or near normal at many readings. When a rise in the serum calcium ultimately occurred there was no increase in weakness. Admittedly, the serum ionized calcium was raised at the only estimation made, but much higher levels are known to occur without comparable weakness (Watson, 1964, personal communication). In Case 2 the total serum calcium was repeatedly normal. If, as we believe, the myopathy in our patients was not a direct effect of changes in extracellular calcium concentration, some other mechanism must be sought. In both cases there was a disturbance of vitamin-D metabolism.
Kodicek (1963) explored the distribution of vitamin D in muscle by autoradiography of muscle sections from rats fed ${ }^{14} \mathrm{C}$-labelled vitamin $\mathrm{D}_{2}$. He found a definite localization of the vitamin within or on the muscle membrane. He stated that vitamin $\mathrm{D}$ appears to modify the structure of cellular or subcellular membranes, and may thus affect the transfer of divalent ions. There is a quantitative correlation between the strength of contraction and calcium entry into the muscle fibre per contraction (Bianchi and Shanes, 1959). It seems likely that a disturbance of vitamin-D metabolism would interfere with this stage of excitation-contraction coupling. We suggest that a disorder of this type may be the cause of myopathy in bone diseases associated with deranged metabolism of vitamin $\mathrm{D}$.

\section{Summary}

Two patients with long-standing muscular weakness are described. One had a parathyroid adenoma and the bone changes of hyperparathyroidism, osteomalacia, and osteosclerosis. The other had osteomalacia due to idiopathic steatorrhoea. In both patients the myopathy improved after treatment of the underlying condition.

The clinical findings and the results of special investigations suggested a similar myopathy in both patients. It is considered significant that the patient with primary hyperparathyroidism also had osteomalacia.

Myopathy may be an important feature of osteomalacia. It is suggested that a similar myopathy may occur in classical vitamin-D-deficiency rickets and renal osteodystrophy.

In both our patients there was little evidence to support the accepted view that muscular weakness with metabolic bone disease is due to a disturbance in extracellular calcium concentration. Disturbed vitamin-D function at the muscle membrane may prove to be the cause of myopathy in metabolic bone disease associated with deranged vitamin-D metabolism.

Dr. G. H. Du Boulay carried out the radiological investigation of Case 1, and Dr. Lyal Watson performed the estimation of ionized serum calcium in this patient. We are grateful to Professor C. E. Dent for permission to publish Case 2. Dr. E. D. R. Campbell kindly allowed us to quote his report on the electromyogram in Case 2. This work was supported by a grant from the Muscular Dystrophy Group of Great Britain.

\section{REFERENCES}

Adams, R. D., Denny-Brown, D., and Pearson, C. M. (1962). Diseases of Muscle, 2nd ed. Kimpton, London.

Albright, F., and Reifenstein, E. C. (1948). The Parathyroid Glands and Metabolic Bone Disease. Baillière, Tindall and Cox, London.

Ball, J. (1963). In Bone Metabolism, edited by H. A. Sissons. Pitman, London.

Beveridge, B., Vaughan, B. F., and Walters, M. N. I. (1959). F. Fac. Radiol. (Lond.), 10, 197.

Bianchi, C. P., and Shanes, A. M. (1959). F. gen. Physiol., 42, 803.

Cohen, S. I., Fitzgerald, M. G., Fourman, P., Griffiths, W. J., and de Wardener, H. E. (1957). Quart. F. Med., 26, 423.

Davies, D. R., Dent, C. E., and Willcox, A. (1956). Brit. med. F., 2, 1133.

Dent, C. E. (1956). Proc. roy. Soc. Med., 49, 715.

(1963). In Bone Metabolism, edited by H. A. Sissons. Pitman,

Fourman, P., McConkey, B., and Smith, J. W. G. (1960). Lancet, 1, 619

Gough, K. R., Lloyd, O. C., and Wills, M. R. (1964). Ibid., 2, 1261.

Henson, R. A., Russell, D. S., and Wilkinson, M. (1954). Brain, 77, 82 Kodicek, E. (1963). In The Transfer of Calcium and Strontium Across Biological Membranes, edited by R. H. Wasserman. Academic Press, New York.

Murphy, T. R., ReMine, W. H., and Burbank, M. K. (1960). Proc. Mayo Clin., 35, 629.

Nordin, B. E. C., and Fraser, R. (1960). Lancet, 1, 947.

Payne, W. W. (1959). In Biochemical Aspects of Neurological Disorders, edited by J. N. Cumings and M. Kremer. Blackwell, Oxford.

Pearson, C. M. (1959). Neurology (Minneap.), 9, 757.

Shy, G M (1960) Proc Ass. Res nerv ment. Dis $38,274$.

Stanbury, S. W. (1963). In Bone Metabolism, edited by H. A. Sissons. Pitman, London.

Vicale, C. T. (1949). Trans. Amer. neurol. Ass., 74, 143.

Walton, J. N., and Adams, R. D. (1958). Polymyositis. Livingstone, Edinburgh.

Wrong, O., and Davies, H. E. F. (1959). Quart. F. Med., 28, 259. 